\title{
Richard Cooper, «Avec le temps»: le voyage poétique en Italie de trois jeunes français, 1535
}

\section{Filippo Fonio}

\section{(2) OpenEdition}

1 Journals

\section{Edizione digitale}

URL: http://journals.openedition.org/studifrancesi/32942

DOI: 10.4000/studifrancesi.32942

ISSN: 2421-5856

\section{Editore}

Rosenberg \& Sellier

\section{Edizione cartacea}

Data di pubblicazione: 1 décembre 2005

Paginazione: 622

ISSN: 0039-2944

\section{Notizia bibliografica digitale}

Filippo Fonio, «Richard Cooper, «Avec le temps»: le voyage poétique en Italie de trois jeunes français, 1535», Studi Francesi [Online], 147 (XLX | III) | 2005, online dal 30 novembre 2015, consultato il 18 avril 2021. URL: http://journals.openedition.org/studifrancesi/32942 ; DOI: https://doi.org/10.4000/ studifrancesi.32942

Questo documento è stato generato automaticamente il 18 avril 2021.

\section{(c) $($ ) $\odot$}

Studi Francesi è distribuita con Licenza Creative Commons Attribuzione - Non commerciale - Non opere derivate 4.0 Internazionale. 
Richard Cooper, «Avec le temps»: le voyage poétique en Italie de trois jeunes français, 1535

Filippo Fonio 


\section{NOTIZIA}

RICHARD COOPER, «Avec le temps»: le voyage poétique en Italie de trois jeunes français, 1535, «Bibliothèque d'Humanisme et Renaissance», LXVI, 3 (2004), pp. 499-524.

Il ms. già Phillips 8293 contiene un poema periegetico non altrimenti noto, del quale lo studioso offre nel presente contributo una sorta di guida alla lettura. Si tratta di un componimento di trecento carte, contrassegnato dalla devise Avec le temps, di versi décasyllabes inframmezzati da dizains e ballate, incentrato sul viaggio in Italia di tre giovani parigini trasferitisi a Lyon, Du Brossay, La Touche e Saincte Jame, compiuto fra il maggio e l'agosto 1535. Cooper mostra come il tono à la Baedeker del poema oscilli costantemente fra notazioni di carattere antiquario - senza un intento erudito né particolari interessi artistici - eno-gastronomico ed etnologico, con un'attenzione particolare per le feste e le celebrazioni a sfondo religioso. I viaggiatori, romipeti, alternano le tappe del loro pellegrinaggio con visite ai monumenti, incursioni nella vita dei luoghi dove soggiornano, incontri di vario tipo e aneddoti. Gli interessi dei tre, ad esempio per la mercatura, l'ambito militare e le costruzioni navali, contribuiscono a fornire al poema un carattere di varietas, mediante l'inserimento di notazioni anche a carattere tecnico in merito a tali soggetti. Ignoriamo fra l'altro se Avec le temps fosse pensato per una diffusione più ampia rispetto a quella di una cerchia di intimi. Il poema va annoverato fra le prime testimonianze dei Grand Tours francesi in Italia, genere del quale il Journal de Voyage di Montaigne rappresenta forse l'esempio più noto per il Cinquecento. 